\title{
The Success and Failure of An Inconvenient Truth and the Stern Report in Influencing Australian Public Support for Greenhouse Policy
}

\author{
MARK MORRISON \\ Institute for Land, Water and Society, \\ School of Business, Charles Sturt University, \\ Bathurst, NSW, Australia
}

\author{
STEVE HATFIELD-DODDS \\ CSIRO Energy Transformed Flagship, Australia, \\ and Centre for Climate Economics and Policy, \\ Crawford School of Economics and Government, \\ Australian National University, Canberra, ACT, \\ Australia
}

\begin{abstract}
Longitudinal surveys were used to identify the effect of increased media climate change reporting because of An Inconvenient Truth, the Stern Report and drought. Results suggest that this was a catalyst for decreased support for policy action at low and moderate cost levels, while support marginally increased at higher costs. Similar results were found for additional information presented within questionnaire suggesting less engaged respondents chose the status quo if information was too complex, while others found the information strengthened the case for action. This highlights tension between ensuring debate is well informed and the risk of disengagement from presenting complex information.
\end{abstract}

\section{Introduction}

Government action to achieve deep cuts in greenhouse gas emissions - like other major policy changes - depends on public support, which depends in turn on perceptions of the consequences of global warming as well as the economic impacts of policy options (Ostrom, 2005). Recent years have seen substantial efforts to increase public support for emission reductions by making the case for action to reduce global warming, including Al Gore's film An Inconvenient Truth (Guggenheim, 2006) and the release

JEL classifications: Q54, D72, Q51, D83, M38, Q58 Correspondence: Mark Morrison, Institute for Land, Water and Society, School of Business, Charles Sturt University, Panorama Ave., Bathurst, NSW 2795, Australia. Email: mmorrison@csu.edu.au of the Stern Report (Stern, 2006). This article examines the impact of these high-profile efforts on Australian public opinion, and demonstrates that unintended effects on public opinion can result from the provision of complicated messages to the community.

Empirical evidence from the environmental economics literature indicates that increasing information about a public good need not always increase public support and willingness to pay (Bergstrom et al., 1989, 1990; Boyle, 1989; Berrens et al., 2004). Providing small but relevant amounts of information have been demonstrated to have no effect on willingness to pay amounts, whereas more substantive amounts of information have been demonstrated to influence willingness to pay (Bergstrom et al., 1989; Boyle, 1989). Theoretically, the Elaboration Likelihood Model suggests that the persuasiveness 
of communication depends on a number of inter-related factors (Eagly \& Chaiken, 1993). The most important factor determining persuasiveness is the quality of the argument made; that is, clear coherent arguments are more persuasive than weak or less conclusive arguments. Evidence in support of this view was provided by Bergstrom et al. (1989) and Azjen et al. (1996). However, as also demonstrated by Azjen et al. (1996), the effect of argument quality depends also on the recipients processing mode: for an argument to be persuasive, recipients must carefully process and evaluate the information received, and their likelihood of doing this depends on their assessment of the personal relevance of the information received. Furthermore, as Azjen et al. (1996, p. 44) noted, recipients of the information must also be 'able to attend to the message and process the arguments it contains'. If respondents lack the motivation or ability to process information carefully, they are more likely to base their information on 'factors that are unrelated to the content of the message', such as 'on relatively superficial cues in the situation, on implicit moods or motivations, or on simple cognitive heuristics' (Azjen et al., 1996, p. 44).

Further evidence about how additional information influences respondents' choices is found in the consumer psychology literature in the area of resource or ego depletion. A series of studies by Pocheptsova et al. (2007), Vohs (2006), Vohs and Faber (2007) and Baumeister et al. (2008) demonstrated that the body has a basic energy supply which influences one's capacity for intelligent decision making. When this resource is depleted through various activities, including the processing of additional information or the making of previous choices, one's capacity for decision making can be impaired. This can lead, as noted by Pocheptsova et al. (2007), to a reduced use of compensatory decision rules and the greater use of a range of heuristics in decision-making, such as focusing on a single attribute, being more likely to choose the status quo alternative, and increased reference dependence. Thus, the extent to which the publicity because of $A n$ Inconvenient Truth and the Stern Report shifted public opinion in favour of greenhouse policy action is expected to depend on the quality of the arguments made, the receptiveness of the public towards them and their capacity to process them.
In this study, we seek to evaluate the effect of externally and internally provided information about climate change impacts on public support for greenhouse policy. We conducted three surveys prior to, during and after the release of An Inconvenient Truth and the Stern Report. We compare the effects of this externally provided information with the internal provision of additional information (within the questionnaire) about the effects of climate change via a split sample treatment. The results indicate similar effects for both the externally and internally provided information. We find evidence that a proportion of respondents were unable or unwilling to process the information provided either externally or internally via the questionnaire and that public support for greenhouse policy declined by up to 20 per cent at low to medium cost levels. We also find that the proportion of the public supporting greenhouse policy is becoming less sensitive to increases in costs associated with the implementation of the policy.

\section{Questionnaire Description}

Two versions of the questionnaire were developed to test the effect of providing minimal and extensive information on respondent support for greenhouse policy. The minimal information treatment provided brief information on the nature and causes of global warming, presented as text, a simple diagram and chart of projected temperature increases over the next 100 years (see Figs 1,2). This acknowledged scientific and media debate on global warming processes (Boykoff \& Boykoff, 2004) and provided a list of weblinks at the end of the survey for participants who were interested in further reading.

The extensive information treatment included this information and also provided an overview of the likely impacts of climate change on Australian temperatures, rainfall, animals and plants, and extreme events, such as drought (Preston \& Jones, 2006), technology options for emissions reductions (Pacala \& Socolow, 2004) and projected global temperature outcomes with significant reductions in emissions. The uncertainty associated with efforts to reduce climate change was also described to respondents with the aid of a diagram.

Both versions of the questionnaire included a referendum where respondents were asked whether they would vote in favour of greenhouse policy at a given cost. The use of referendums of this genre is consistent with the contingent 
Figure 1

Diagram Describing the Causes of Global Warming

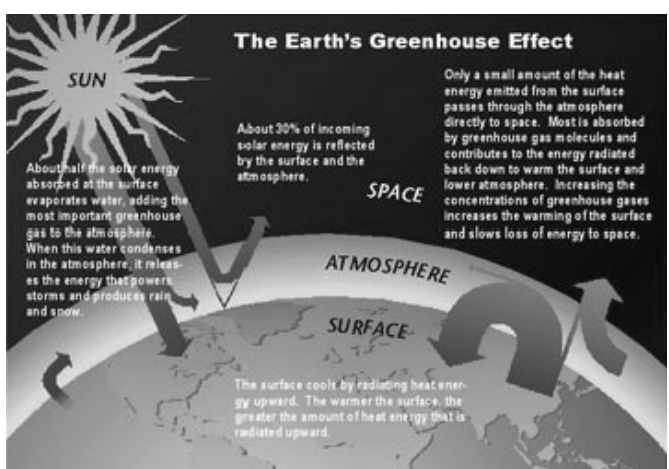

Notes: We would next like to describe to you the problem of global warming and why it occurs. Global warming results from using coal, natural gas and oil for energy production. The use of these products leads to the emission of various greenhouse gases, such as carbon dioxide. These gases have accumulated in our atmosphere over the past 200 years. The problem is that these gases trap heat in the earth's atmosphere, which is causing the world's average temperature to increase. These processes involve long lags as most greenhouse gases continue to trap heat for 10-100 years once in the atmosphere.

valuation literature from environmental economics, and the principles of that literature were therefore used to guide the design of the questionnaire. The referendum question format is well established in the contingent valuation literature. This format is considered to have strong theoretical properties compared with other formats (Hoehn \& Randall, 1987; Carson \& Groves, 2007), and its use was recommended by the NOAA panel on contingent valuation following the Exxon Valdez oil spill (Arrow et al., 1993). In this format, respondents are presented with two alternatives, one of which usually represents the status quo, whereas the other represents the alternative scenario to be valued or evaluated. Respondents are asked which alternative they would vote for in a referendum, and are given a not sure option (recommended to reduce yea-saying behaviour (Arrow et al., 1993)). An example is shown in Figure 3.

The questionnaires for both treatments stated that policy action would be accompanied by lower average incomes because of higher costs and increased prices for goods and services. The contingent valuation literature refers to this as the 'payment vehicle', representing one aspect of the trade-off to be considered by the respondent
FIGURE 2

Chart of Projected Temperature Increases Over the Next 100 Years

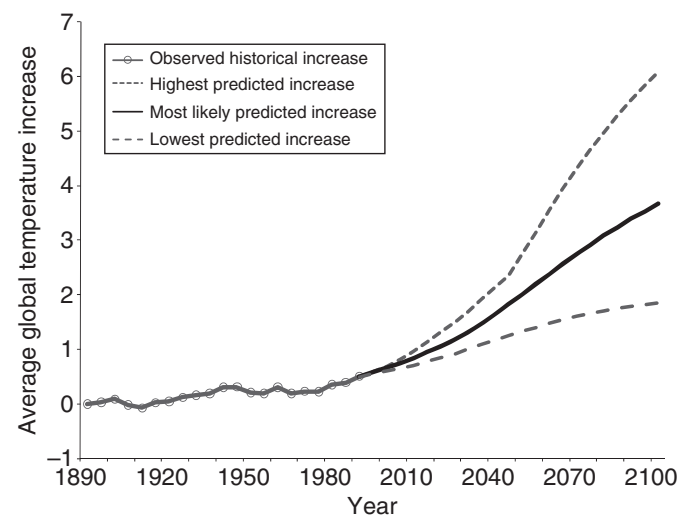

Notes: Over the past century, average temperatures have risen by approximately $0.7^{\circ} \mathrm{C}$. Further increases in temperature and changes to rainfall patterns are expected around the world, as shown in the figure. Scientific experts largely agree that average global temperatures will rise by at least $1.5^{\circ} \mathrm{C}$. The speed and extent of the temperature increases depend on a range of factors, including future policy choices and the level of future emissions from burning fossil fuels, and so are not able to be predicted precisely. Understanding upper and lower predictions of temperature change. Scientific models usually provide a range of estimates. The centre line is the most likely outcome. The upper dashed line is the highest estimate predicted by a model, whereas the lower dashed line is the lowest estimate predicted by a model. The centre line is the most likely outcome but there is still some chance that the upper or lower will occur.

when choosing whether to support policy action to reduce emissions. In both treatments, the payment vehicle was described as follows:

Low emissions technologies for electricity and transportation tend to cost more than existing technologies. This will lead to higher prices for electricity, transport and motor vehicles. This will flow through to higher prices for some other goods and services.

At a national level, reducing greenhouse gas emissions would reduce the rate of economic growth in Australia.

\section{What do you think?}

We would like to know what you think about trading off some future economic growth in return for reducing the risk of global warming. 
Figure 3

Example Referendum Question

Please consider the following referendum. If you were asked to choose between the following two alternatives, realistically which one would you vote for?

\begin{tabular}{|c|c|}
\hline Option A: & Option B: \\
\hline $\begin{array}{l}\text { Continue current practice and accept that } \\
\text { serious global warming very likely }\end{array}$ & $\begin{array}{l}\text { Reduce the likelihood of serious global } \\
\text { warming, and accept lower economic growth } \\
\text { and income }\end{array}$ \\
\hline $\begin{array}{l}\text { If no further efforts are made to reduce } \\
\text { greenhouse gas emissions, it is estimated that: }\end{array}$ & $\begin{array}{l}\text { If significant efforts are made to reduce } \\
\text { greenhouse gas emissions, it is estimated that: }\end{array}$ \\
\hline $\begin{array}{l}\text { - Average temperatures are most likely to } \\
\text { rise by around } 3.7^{\circ} \mathrm{C} \text { by } 2100\end{array}$ & $\begin{array}{l}\text { - Average temperatures are most likely to } \\
\text { rise by around } 2.5^{\circ} \mathrm{C} \text { by } 2100\end{array}$ \\
\hline $\begin{array}{l}\text { - There is some chance that average } \\
\text { temperatures will rise by around } 6^{\circ} \mathrm{C}\end{array}$ & $\begin{array}{l}\text { - There is some chance that average } \\
\text { temperatures will rise by around } 3^{\circ} \mathrm{C}\end{array}$ \\
\hline $\begin{array}{l}\text { - Average household income increases } \\
\text { from its current level of } \$ 47,600 \text { to } \\
\$ 64,200 \text { in } 2020\end{array}$ & $\begin{array}{l}\text { - Average household income increases } \\
\text { from its current level of } \$ 47,600 \text { to } \\
\$ 60,300 \text { in } 2020\end{array}$ \\
\hline \multirow[t]{2}{*}{$\begin{array}{l}\text { - Greenhouse policy has no impact on } \\
\text { average household income }\end{array}$} & $\begin{array}{l}\text { - This increase is } \$ 3,900 \text { less than } \\
\text { without action }\end{array}$ \\
\hline & $\begin{array}{l}\text { - Future average household income is } 6 \% \\
\text { lower than it would be without action }\end{array}$ \\
\hline $\begin{array}{l}\text { These estimates are in today's dollars, taking } \\
\text { out inflation. }\end{array}$ & $\begin{array}{l}\text { These estimates are in today's dollars, taking } \\
\text { out inflation. }\end{array}$ \\
\hline
\end{tabular}

This payment vehicle, without the final statement on reduced economic growth, has been used in other contingent valuation studies (Boyle et al., 1994; Boyle, 2003), including studies valuing reducing the impacts of global warming (Berrens et al., 2004).

The level of impact presented as part of the alternative was varied across respondents so that it is possible to determine how support for an environmental improvement is related to economic costs. The policy impacts, that is the economic costs, described to respondents were based on economic modelling of achieving a 60 per cent reduction of Australian greenhouse emissions by 2050 (Allen Consulting Group, 2006). This suggested policy impacts on average income of up to 1.4 per cent in 2020 , with an increase in real income with policy action of 23-25 per cent by 2020 (depending on the indicator chosen). These impacts are larger than the median estimates of global policy impacts of stabilisation of greenhouse gasses around 450 ppm (Grubb et al., 2005; Edenhofer et al., 2006; IPCC WG3, 2007), consistent with expectations that Australia is likely to face above average economic impacts (Energy Futures Forum, 2006; Hatfield-Dodds et al., 2007; Australian Government, 2008). These impacts were used to establish the lower end of the range of impacts presented to respondents, with impacts described to respondents ranging from 2 to 24 per cent of income in 2020 , equivalent to a forgone gain in income of $\$ 1200-15,400$ in 2020. It is important to note that these impacts are up to 12 times larger than the largest impacts suggested by Treasury modelling of the Carbon Pollution Reduction Scheme (Australian Government, 2008), which projected impacts of 1.1-1.6 per cent of gross domestic product (GDP) and 1.3-2.0 per cent of gross national product (GNP), with GNP per capita rising from $\$ 50,400$ in 2008 to $\$ 54,700-55,200$ in 2020 across four scenarios, rather than $\$ 55,900$ without policy action.

An issue with surveys of this kind is the potential for hypothetical bias, particularly yea-saying where respondents vote in favour of a referendum, when if actually faced with this choice they would vote no (Blamey et al., 1999). A number of elements intended to reduce 
yea-saying and improve the realism and reliability of the results were therefore incorporated into the questionnaire.

The first strategy employed was to express the impacts tangibly in both dollars and percentages, and to focus on impacts in 2020 on the basis that these are more likely to be salient to respondents than impacts in 2050. These measures also help ensure that the payment vehicle is credible and fits comfortably with respondents' pre-existing expectations and outlooks.

The second strategy was to include a 'cheap talk' script as an entreaty or commentary just prior to asking the referendum question. This approach has been found effective at reducing yea-saying (Cummings \& Taylor, 1999), and alternative versions of this approach have been tested in a number of studies (List, 2001; Murphy et al., 2005). Overall, the evidence indicates that cheap talk differs in its effectiveness, but it is most effective for public goods where respondents are relatively inexperienced with the good being valued, and for moderate to high bid levels, as is the case in this study. The study used a short version of a cheap talk script developed by Olar et al. (2007), which uses simpler language than other scripts. The script is as follows:

Before answering the next question, we would like to let you know about a problem we have with asking people how they would vote in a referendum. How people say that they will vote in a survey such as this one is often not a reliable indication of how people would vote if the referendum were actually held. In surveys, some people ignore the monetary and other sacrifices that they would really have to make if their vote won a majority and became law. We call this hypothetical bias. In surveys that ask people if they would pay more for certain services, research has found that people may say that they would pay 50 per cent more than they actually would pay in real referenda.

It is very important that you "vote" as if this were a real vote. You need to imagine that you were voting about what would happen to your actual future income.

\section{Sampling Logistics}

Three rounds of sampling were conducted prior, during and after the release of An Inconvenient Truth and the Stern Report. All surveys were conducted through a general population survey using an internet panel, as has been done with other surveys of community support for greenhouse policy (e.g. Berrens et al., 2004). Internet surveys have been demonstrated to be a cost-effective method of obtaining data for population surveys (Li et al., 2004a). These surveys were part of a larger experimental design which included different treatments that sought to examine how communication of climate change impacts affects support for public policy, and the community's willingness to pay for climate change policy.

Prior to the release of An Inconvenient Truth and the Stern Report, split samples were collected for the minimal and extensive information treatments. This occurred from 26 September to 5 October 2006. Following this initial

TABLe 1

Sample and Population Characteristics

\begin{tabular}{|c|c|c|c|c|}
\hline Sample date & $\begin{array}{l}26 \text { September-5 } \\
\text { October } 2006\end{array}$ & $\begin{array}{l}26 \text { September-5 } \\
\text { October } 2006\end{array}$ & $\begin{array}{c}26 \text { October-3 } \\
\text { November } 2006\end{array}$ & $\begin{array}{l}30 \text { November-6 } \\
\text { December } 2006\end{array}$ \\
\hline Wave & 1 & 1 & 2 & 3 \\
\hline Sample size & 266 & 269 & 126 & 136 \\
\hline Information provided & Extensive & Minimum & Minimum & Minimum \\
\hline Age (years) & 47.62 & 46.3 & 43.5 & 48.7 \\
\hline Gender $(\% \mathrm{~F})$ & 43 & 48 & 56 & 43 \\
\hline Household income & $\$ 64,836$ & $\$ 63,866$ & $\$ 60,123$ & $\$ 64,943$ \\
\hline Have children $(\%)$ & 72 & 70 & 67 & 68 \\
\hline Confidence in climate science ${ }^{\dagger}$ & 3.44 & 3.41 & 3.60 & 3.46 \\
\hline Number of respondents & 266 & 269 & 126 & 136 \\
\hline
\end{tabular}

Note: ${ }^{\dagger} 1=$ not at all confident, $5=$ fully confident. 
survey, media attention to a continuing drought rose sharply as farming conditions deteriorated, authorities announced tighter urban water restrictions and Al Gore's film An Inconvenient Truth was released in Australia. Media attention then peaked with the release of the Stern Report. The second survey was then conducted from 26 October to 3 November 2006, coinciding with the release of the Stern Report. The third survey was then implemented 4 weeks later (30 November to 6 December 2006).

The sociodemographic characteristics of the four samples, the population characteristics and size of each subsample are shown in Table 1. The sociodemographic characteristics of the subsamples are similar to each other, and similar to the Australian population. According to the 2006 census, the average Australian household income was $\$ 61,058,49.4$ per cent of the population were female, and the average age of those over 18 years was 46.3 years.

\section{Results}

In the referendum question, respondents had three possible responses: they could vote in favour of the referendum, against it, or indicate that they were not sure. Their responses are therefore ordered, implying the need to use ordered regression techniques to model these data. The use of the ordered logit model therefore allows explicit modelling of not sure responses without either recoding them as no votes or excluding them from the sample. The use of regression analysis allows the modelling of the effect of household cost on support for the referenda, as well as other variables, such as treatment effects, confidence in climate science and other attitudes, and sociodemographic variables. The ordered logit model is commonly specified as follows:

$$
y_{i}^{*}=\beta^{\prime} x_{i}+\varepsilon_{i},
$$

where $y_{i}$

$$
\begin{array}{ll}
=0 & \text { if } y_{i} \leq \mu_{0} \\
=1 & \text { if } \mu_{0}<y_{i} \leq \mu_{1} \\
=2 & \text { if } \mu_{1}<y_{i} \leq \mu_{2} \\
\cdots & \\
=J & \text { if } y_{i}>\mu_{J-1} .
\end{array}
$$

The free parameters $\mu$ represent the cut-off between ranks. Further details about this model can be found in Greene (1993) and Train (2003).
A general to specific modelling procedure has been followed in this study. Variables have been included where they have been found to be significant using a likelihood ratio test. Treatment variables have been included in the model as main effects as well as through interaction with household cost. Dummy variables have been used for treatment variables. Two separate ordered logit models have been estimated to demonstrate the influence of: (i) the Stern Report and An Inconvenient Truth and (ii) greater information provision on public support for greenhouse policy.

A particular challenge with logit models is that differences in model variance across datasets can affect the validity of hypothesis testing. In discrete choice models, such as the ordered logit, there is a confounding between the betacoefficients and the scale parameter. In most applications, the scale parameter is arbitrarily set equal to one; however, in reality, it is inversely proportional to the model variance. To correct for differences in variance, Swait and Louviere (1993) recommend use of a grid-search procedure that involves re-scaling subsamples within a dataset until the log-likelihood of the pooled model is minimised to correct for variance differences between datasets. This procedure was followed in this analysis. It should be noted, however, that this represents only a partial correction for the potential bias caused by the confounding between variance and model parameters. In the wider literature on discrete choice models, work has been conducted on developing models that allow for different errors across alternatives and respondents (e.g. Salisbury \& Feinberg, 2010; Fiebig et al., 2010). However, as models of this type are not yet available for ordered data, they have not been utilised here.

The variables included in the regression models are described in Table 2. Expectations about the sign of each of the variables are also included. The anticipated sign of a number of the variables is relatively self-explanatory (e.g. cost, confidence, temperature). For a couple of variables - age and children - the sign is uncertain. For age, a positive sign might be expected as younger people are generally more pro-environmental and more likely to experience the impacts of global warming; conversely it might be expected that older people have stronger bequest motives and may be more willing to support future costs that they are unlikely to pay. For children, a positive sign might be 
TABLE 2

Variable Definition and Anticipated Signs

\begin{tabular}{|c|c|c|}
\hline Variable & Definition & Expected sign \\
\hline Wave 3 & $\begin{array}{l}\text { Dummy variable if sampling occurred immediately after } \\
\text { Stern Report and An Inconvenient Truth were released. } \\
\text { Missing category is sampling prior to the release }\end{array}$ & $+/-$ \\
\hline Wave 2 & $\begin{array}{l}\text { Dummy variable if sampling occurred } 6 \text { weeks after } \\
\text { An Inconvenient Truth and the Stern Report were released. } \\
\text { Missing category is sampling prior to the release }\end{array}$ & $+/-$ \\
\hline Pro-environment & $\begin{array}{l}\text { Dummy variable indicating that when respondents have } \\
\text { heard about proposed projects where there is a conflict } \\
\text { between development and the environment, they have } \\
\text { tended to be pro-environment rather than pro-development } \\
\text { or neither pro-environment nor pro-development }\end{array}$ & + \\
\hline Pro-development & $\begin{array}{l}\text { Dummy variable indicating that when respondents have heard } \\
\text { about proposed projects where there is a conflict between } \\
\text { development and the environment, they have tended to be } \\
\text { pro-development rather than pro-environment or neither } \\
\text { pro-environment nor pro-development }\end{array}$ & - \\
\hline Confidence & $\begin{array}{l}\text { Confidence in scientific predictions about global warming } \\
\text { ( } 1 \text { - not at all confident, } 5 \text { - fully confident })\end{array}$ & + \\
\hline Temperature & $\begin{array}{l}\text { Perceptions of temperature change }(1-\text { falling, } \\
2 \text { - staying the same, } 3 \text { - falling })\end{array}$ & + \\
\hline Age & Age (years) & $?$ \\
\hline Children & Dummy variable representing that respondent has children & $?$ \\
\hline Cost & Expected decrease in household income in 2020 & - \\
\hline Cost $\times$ Wave 2 & Cost $\times$ Wave 2 & + \\
\hline Cost $\times$ Wave 3 & Cost $\times$ Wave 3 & + \\
\hline Full information & $\begin{array}{l}\text { Dummy variable representing use of maximum information } \\
\text { treatment }\end{array}$ & $+/-$ \\
\hline Full information $\times$ Cost & Full information $\times$ Cost interaction & + \\
\hline
\end{tabular}

expected due to bequest motives; however, a negative sign could result from lesser ability to pay due to the costs associated with having children. The Waves 2 and 3 coefficients, which show the effect of information provided through the media over time, should have a positive sign if the publicity surrounding these releases has a positive influence on public support. However, the sign could also be negative if resource or ego depletion from the provision of additional information during Waves 2 and 3 lead to a larger proportion of respondents choosing the status quo alternative. Similarly, if the provision of more information within the survey leads to greater public support, the Full information dummy should have a positive sign, but if the provision of more information within the survey leads to less public support because of resource depletion, the dummy could have a negative sign. While the effects of these dummy variables are indeterminate a priori, the Wave $2 \times$ Cost, Wave $3 \times$ Cost and Full information $\times$
Cost interactions are expected to have a positive sign. This is because more information about the consequences of global warming provided via the media or within the questionnaire would be expected to reduce the cost sensitivity of the sample.

The two ordered logit models estimated to further investigate the effects: (i) externally provided information (via An Inconvenient Truth and media coverage of the Stern Report and drought conditions); and (ii) internally providing additional information (via the questionnaire) on public support for greenhouse policy are presented in Table 3. As discussed earlier, to correct for differences in variance across datasets, a grid-search procedure was used. Moderate scale differences were identified for both Wave 2 (1.48) and Wave 3 (1.32) and minor scale differences for the Full information treatment (0.98).

Both models have reasonable explanatory power and there is evidence of construct validity as demonstrated by the various demographic and 
TABLE 3

Ordered Logit Regression Models for Externally and Internally Provided Information Treatments

\begin{tabular}{|c|c|c|}
\hline Variable & $\begin{array}{c}\text { External } \\
\text { provided } \\
\text { information } \\
\text { treatments }\end{array}$ & $\begin{array}{c}\text { Externally } \\
\text { provided } \\
\text { information } \\
\text { treatments }\end{array}$ \\
\hline$\mu_{1}$ & $\begin{array}{c}0.268 \\
(0.568)\end{array}$ & $\begin{array}{c}0.698 \\
(0.618)\end{array}$ \\
\hline$\mu_{2}$ & $\begin{array}{l}1.133 * * * \\
(0.567)\end{array}$ & $\begin{array}{l}1.746 * * * \\
(0.623)\end{array}$ \\
\hline Pro-environment & $\begin{array}{c}0.050 \\
(0.203)\end{array}$ & $\begin{array}{c}0.077 \\
(0.229)\end{array}$ \\
\hline Pro-development & $\begin{array}{l}-0.820 * * * \\
(0.333)\end{array}$ & $\begin{array}{c}-0.955^{* * * *} \\
(0.362)\end{array}$ \\
\hline Confidence & $\begin{array}{l}0.594 * * * \\
(0.093)\end{array}$ & $\begin{array}{l}0.566 * * * \\
(0.100)\end{array}$ \\
\hline Temperature & $\begin{array}{l}0.347 * * * \\
(0.130)\end{array}$ & $\begin{array}{l}0.349 * * * \\
(0.150)\end{array}$ \\
\hline Age & $\begin{array}{l}0.023 * * * \\
(0.008)\end{array}$ & $\begin{array}{l}0.030 * * * \\
(0.009)\end{array}$ \\
\hline Children & $\begin{array}{c}-0.552 * * \\
(0.235)\end{array}$ & $\begin{array}{c}-0.025 \\
(0.248)\end{array}$ \\
\hline Cost & $\begin{array}{l}-0.142 * * * \\
(0.028)\end{array}$ & $\begin{array}{l}-0.144 * * * \\
(0.029)\end{array}$ \\
\hline Wave 2 & $\begin{array}{l}-1.063 * * * \\
(0.404)\end{array}$ & $\mathrm{ND}$ \\
\hline Wave 3 & $\begin{array}{l}-1.642 * * * \\
(0.404)\end{array}$ & ND \\
\hline Full information & ND & $\begin{array}{c}-1.227 * * * \\
(0.384)\end{array}$ \\
\hline Cost $\times$ Wave 2 & $\begin{array}{l}0.083 * * \\
(0.042)\end{array}$ & ND \\
\hline Cost $\times$ Wave 3 & $\begin{array}{l}0.122 * * * \\
(0.041)\end{array}$ & ND \\
\hline $\begin{array}{l}\text { Cost } \times \text { Full } \\
\text { information }\end{array}$ & ND & $\begin{array}{l}0.133 * * * \\
(0.039)\end{array}$ \\
\hline $\begin{array}{l}\text { Rho-square } \\
\text { (McFadden) }\end{array}$ & 0.131 & 0.111 \\
\hline$N$ & 531 & 535 \\
\hline
\end{tabular}

Notes: Standard errors are in parentheses. $* * *$ Significance at 1 per cent, **significance at 5 per cent. ND, no data.

attitudinal variables that are significant. These include confidence in scientific predictions, perceptions of temperature change and prodevelopment attitude, and all had the expected signs. Age was also significant and positively signed in both models, whereas children was significant and negatively signed in the time treatments model only. The positive sign for age is interesting as in two previous studies for greenhouse policy it has been found to have a negative sign, indicating that younger respondents are more likely to be willing to pay to reduce global warming (Berk \& Schulman, 1995; Li et al., 2004b). There is, however, less information in the literature about the effect of having children on willingness to pay to reduce global warming, although the literature suggests that the effects can be varied (Morrison et al., 1999; Teal \& Loomis, 2000; Dupont, 2004). Among the attitudinal and demographic variables, the only insignificant coefficient is for pro-environment.

The results for the externally provided information (via An Inconvenient Truth and the Stern Report) indicate a strong and significant dummy and interaction effects for the second and third sampling wave. The sign of the cost interaction for both Waves 2 and 3 is as expected (+), indicating that the cost curve is more inelastic after the treatment. That is, after the Stern Report and An Inconvenient Truth, respondents were less responsive to cost increases and were more likely to vote in support of the referendum, even in the face of relatively large cost increases. The sign of the dummy variables for both Waves 2 and 3 is, in contrast, negative. Given the positive interaction with cost, this means that at low costs ( $\$ 1200$ and $\$ 3900$ per year), a lower proportion of respondents voted in favour of the referendum after the release of An Inconvenient Truth and the Stern Report than before. At low bids, there has been a similar increase in both the number of respondents who voted no and those who voted not sure. At the highest cost level support is marginally higher. These results are plotted in Figure 4. The results suggest that resource or ego depletion from increased and more complex information about global warming in the media may have lead to a proportion of respondents resorting to the use heuristics such as choosing the status quo alternative. Secondly, the results suggest that support for climate change policy is becoming more inelastic or even lexicographic with the increasing flatness of the curve.

Interestingly, similar results occur for internally provided information (comparing different levels of information provided within the questionnaire). The interaction of the Full information variable with Cost is positively signed and significant, as expected. The Full information dummy variable again has a negative sign, indicating that the provision of additional information within the survey has reduced support for climate change policy at lower cost levels. This is shown in the third column of Table 3 (and in Fig. 5). 
Figure 4

Proportion of Respondents Voting Yes in Waves 1, 2 and 3

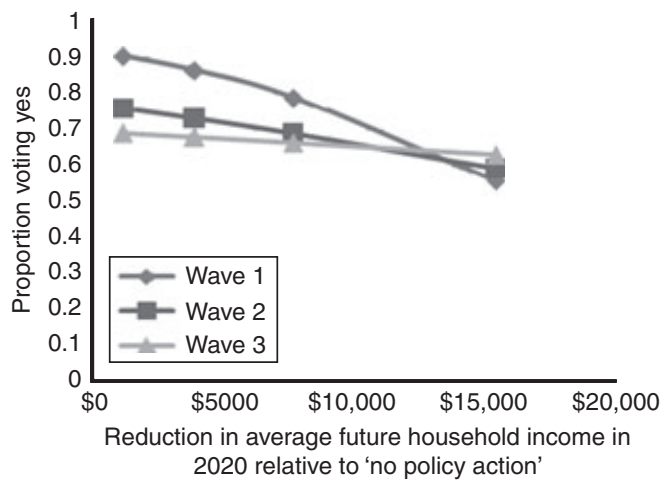

FIGURE 5

Proportion of Respondents Voting Yes in Minimum and Full Information Treatments

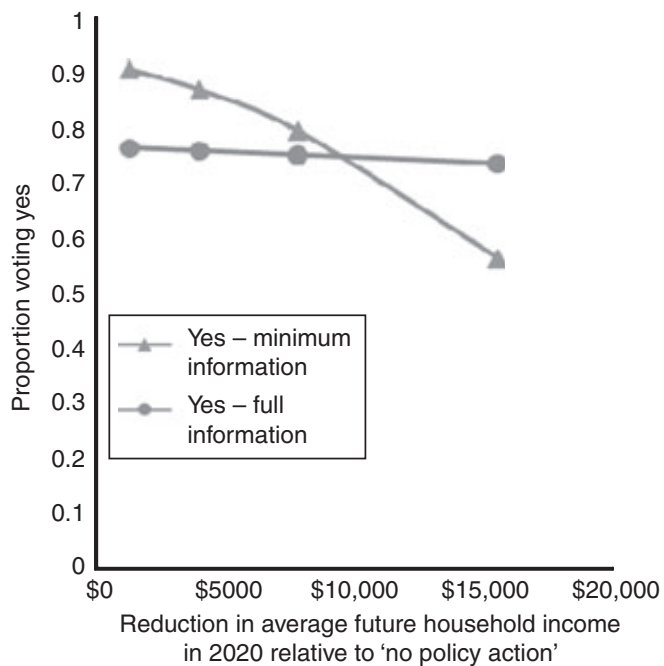

The predicted support levels in this study can be compared with results from other studies, although these other studies have not also sought to examine the effect on public support of providing additional information, which is the main goal of this study. Overall, levels of public support for policy action found in this study are similar to levels found in other studies. For example, studies by Costantoura (2007) and a review of opinion polls by The Climate
Institute (2007) show a clear trend increase in public concern and support for policy action, rising from around 40 per cent in 2003, to 70 per cent in 2005-2006, and 76 per cent in 2007. The significant increase in support between 2003 and 2006 appears to be associated with Australia's prolonged drought and urban water shortages, and an emerging perception of climate change as a security issue, with the Lowy Institute $(2005,2006)$ finding that climate change and 'global environmental issues' were ranked in the top three perceived threats to Australia's national interests (just below 'international terrorism' and 'hostile nations acquiring nuclear weapons'). These studies indicate slightly lower levels of support for action than the survey reported here for Wave 1, but similar results for Wave 2 and Wave 3 at policy relevant cost levels.

The study results are also consistent with available other findings on willingness to support policy action at different levels of national or household economic impact. In a survey in October 2006, prior to the release of the Stern Report, 68 per cent of respondents agreed with the statement that 'Global warming is a serious and pressing problem. We should begin taking steps now even if this involves significant costs' (Newspoll, 2007). A survey in February 2007 found that 76 per cent of people considered climate change a major problem, and a further 17 per cent considered it a minor problem. In the same survey, 20 per cent of respondents reported they would be prepared to pay a lot more, and 57 per cent a little more, for energy if this helped to reduce greenhouse emissions (The Climate Institute, 2007). Carson et al. (2010) found in a study conducted in August 2008 that 65.7 per cent of respondents see global warming as an extremely or very serious problem, and 21.4 per cent see it as a problem. Carson et al. (2010) also reported that 82.6 per cent of respondents reject the idea of not adopting a plan to reduce greenhouse gasses and that 84.7 per cent believe that Australia should go ahead and cut emissions regardless of what other countries do. Thus, overall, our results are comparable with other studies in terms of the magnitude of community support for climate change policy.

Lastly, the survey findings on changes in support over the three waves of the study can be compared with independent time series data on the share of respondents nominating 'global 
FIGURE 6

Proportion of Public Nominating Climate Change or Environment in their Top Three Issues of Most Importance

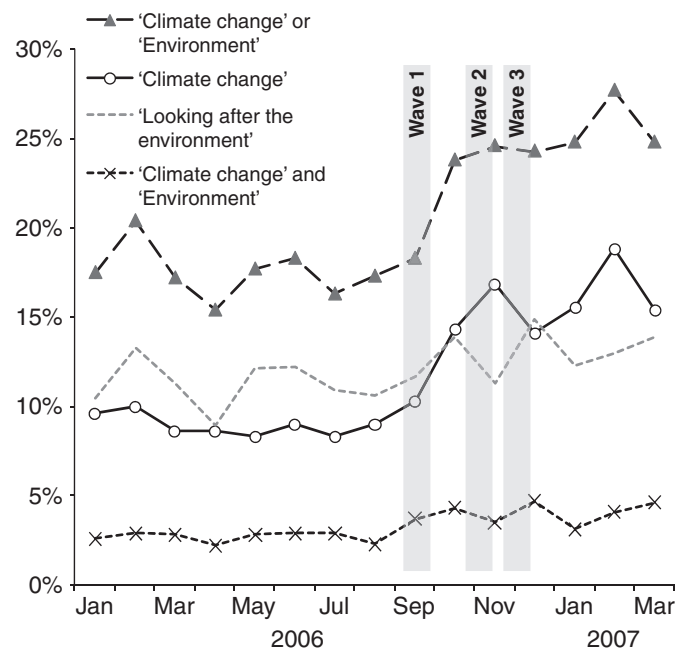

Notes: Data from Roy Morgan Single Source poll. 'Which three issues are the most important to you?' $(n=58,294)$. Grey columns indicate approximate timing of the three waves of survey implementation.

warming and climate change' as one of the three public issues of most importance to them, as shown in Figure 6. The Roy Morgan poll indicated that in both Waves 2 and 3 a higher proportion of respondents (from 18 to 24 per cent) were nominating climate change as being one of the top three issues of importance to them. Thus, the proportion of the community who are clearly very concerned about climate change is increasing, but this group only represents about a quarter of the community. Nonetheless, it does indicate growth in the proportion of the community that are strongly in favour of climate change policy, which we interpret as being consistent with our finding that the support for climate change policy is becoming more inelastic. Thus, there is evidence in the wider literature that support is becoming more inelastic, as we also identified, but previous polling and surveys have not identified that the proportion of the community supporting climate change policy at low and medium cost levels has declined with increased provision of information.

\section{$V$ Conclusions}

Government implementation of policy to reduce greenhouse emissions is dependent in part on public support for action, which is in turn influenced by information on the costs, benefits and risks associated with climate change and potential policy responses. The results and analysis presented in this article gives rise to four major findings relevant to understanding what has influenced community support for greenhouse policy.

First, we find that Australian public support for action to reduce greenhouse gas emission and the likelihood of serious global warming is high. The survey results suggest that at least 70 per cent of Australian adults support policy action, even where this involves a cost or forgone gain of more than $\$ 1200$ per year of household income by 2020 - matching the projected impact of the proposed Carbon Pollution Reduction Scheme (Australian Government, 2008). This finding is consistent with other surveys indicating public concern and general support for policy action has increased to over 70 per cent, in part because of the impacts of prolonged drought and water shortages (Costantoura, 2007; The Climate Institute, 2007).

Second, we find that the release of the Al Gore documentary An Inconvenient Truth and the Stern Report as well as increased media reporting of drought were associated with declines of up to 20 per cent in total level of support for policy options with low to medium levels of impact. While it cannot be argued that there is a causal link between this media activity and declining support, it appears to have been a catalyst. This was a surprising result, and based on other evidence from the literature we consider the most likely explanation for this finding is that some respondents appear to have found the additional information too complex or too contested, and so that there has been a shift in the distribution of those voting 'yes' to 'no' or 'not sure'. As a number of respondents only had low willingness to pay this may be an indicator that they also had limited motivation to process the additional information (Azjen et al., 1996). This finding is consistent with observations in the economics and marketing literatures that complexity increases the propensity of respondents to choose the status quo (Swait \& Adamowicz, 2001; Dellaert \& Stremersch, 2005; Moon et al., 2005), and that respondents are more likely to vote no when the task of 
choosing a preferred option is 'too complex, or when they are uncertain about the trade-offs they would be willing to make' (Adamowicz et al., 1998, p. 73). We do, however, recognise that there are other possible explanations for this phenomenon. For example, it is possible that the additional information may have caused some respondents to change their conclusions about the merits of a policy change and to vote against the proposal. This could occur if the additional information led some respondents to consider the proposal to be more consequential and thus more carefully evaluate the proposal. However, we consider this to be a less satisfactory explanation as the decline in yes votes was only observed at lower bid levels.

Third, we find very similar effect associated with the provision of more comprehensive information about the consequences of climate change within the survey questionnaire. This supports the interpretation that the observed reduction in support associated with the release of An Inconvenient Truth, the Stern Report and the increased media reporting about the drought can be attributed to the additional complexity and information processing demands associated with the additional information.

Fourth, while there was a decline in support at low and medium cost levels, the release of $A n$ Inconvenient Truth and the Stern Report commissioned by the UK Government in 2006 was associated with the proportion of respondents supporting climate change policy becoming much less cost sensitive, so that the demand curve for policy action (representing 'willingness to support' a non-rival non-excludable good) becomes highly inelastic. This suggests that the support for policy action after additional information is provided is only marginally impacted by the level of cost associated with policy action - despite respondents being presented with costs more than 10 times larger than those suggested by economic modelling (Hatfield-Dodds et al., 2007; Australian Government, 2008). This finding is consistent with observations that many Australians now consider action on climate change is a fundamental issue that they are not willing to trade-off against economic gains, reflected in characterisations of climate change as a national security issue (Lowy Institute, 2005, 2006) or as a moral imperative (The Climate Institute, 2007).

Overall, we find that increased information on climate change and the impacts of policy action is associated with a decrease in public willingness to support emissions reductions at low and medium levels of cost, but an increase in support at the highest level of cost. The analysis presented suggests this result reflects two processes. First, the increased information causes some weakly engaged supporters to disengage, and switch from support for low cost action to support for the status quo. Second, the increased information causes more engaged respondents to become less cost-sensitive, increasing willingness to pay, which is reflected in higher support even if the costs of policy action are much higher than those suggested by economic modelling and analysis. The disengagement effect outweighs the willingness to pay effect by engaged respondents at low cost levels, as in the absence of additional information weakly engaged respondents support low and moderate cost action to reduce emissions but not high cost action. At high cost levels, the increased willingness to pay effect dominates.

Therefore, we find that explaining the case for action on climate change is not straightforward, and must manage the tension between ensuring public debate is well informed, and the risk of disengagement by some members of the public when issues are perceived as complex or highly contested. This tension underlies our finding of the mixed success of An Inconvenient Truth and the Stern Report in persuading the Australian public of the case for action. The findings highlight the importance of ensuring that community information about policy choices are communicated as simply as possible, to help include as many members of the public as possible in the public debate. However, the findings also demonstrate that it is important to ensure that public debate is well-informed on issues, such as responding to climate change, where both policy action and inaction involves substantial longterm costs, even if such debate is relatively complex and thus carries a risk of disengagements by some members of the public.

\section{REFERENCES}

Adamowicz, W., Boxall, P., Williams, M. and Louviere, J. (1998), 'Stated Preference Approaches for Measuring Passive Use Values: Choice Experiments and Contingent Valuation', American Journal of Agricultural Economics, 80, 64-75.

Allen Consulting Group (2006), Deep Cuts in Greenhouse Gas Emissions: Economic, Social and Environmental Impacts for Australia. Report to the 
Australian Business Roundtable on Climate Change, ACG, Melbourne. [Cited 19 November 2010.] Available from: http://www.businessround table.com.au

Arrow, K., Solow, R., Portney, P.R., Leamer, E.E., Radner, R. and Schuman, H. (1993), 'Report of the NOAA Panel on Contingent Valuation', Federal Register, 58, 4601-14.

Australian Government (2008), Australia's Low Pollution Future: The Economics of Climate Change Mitigation. Commonweatlh of Australia, Canberra.

Azjen, I., Brown, T.C. and Rosenthal, L.H. (1996), 'Information Bias in Contingent Valuation: Effects of Personal Relevance, Quality of Information, and Motivational Orientation', Journal of Environmental Economics and Management, 30, 43-57.

Baumeister, R.F., Sparks, E.A., Stillman, T.F. and Vohs, K.D. (2008), 'Free Will in Consumer Behaviour: Self-Control, Ego Depletion and Choice', Journal of Consumer Psychology, 18, 4-13.

Bergstrom, J.C., Stoll, J.R. and Randall, A. (1989), 'Information Effects in Contingent Markets', American Journal of Agricultural Economics, 71, 685-91.

Bergstrom, J.C., Stoll, J.R. and Randall, A. (1990), 'The Impact of Information on Environmental Commodity Valuation Decisions', American Journal of Agricultural Economics, 72, 614-21.

Berk, R. and Schulman, D. (1995), 'Public Perceptions of Global Warming', Climatic Change, 29, 1-33.

Berrens, R.P., Bohara, A.K., Jenkins-Smith, H.C., Silva, C.L. and Weimer, D.L. (2004), 'Information and Effort in Contingent Valuation Surveys: Application to Global Climate Change Using National Internet Samples', Journal of Environmental Economics and Management, 47, 331-63.

Blamey, R.K., Bennett, J.W. and Morrison, M.D. (1999), 'Yea-Saying in Contingent Valuation Surveys', Land Economics, 75, 126-41.

Boxall, P., Adamowicz, V. and Moon, A. (2009), 'Complexity in Choice Experiments: Choice of the Status Quo Alternative and Implications for Welfare Measurement', Australian Journal of Agricultural and Resource Economics, 53(4), 503-19.

Boykoff, M.T. and Boykoff, J.M. (2004), 'Balance as Bias: Global Warming and the US Prestige Press', Global Environmental Change, 14, 125-36.

Boyle, K.J. (1989), 'Commodity Specification and the Framing of Contingent Valuation Questions', Land Economics, 65, 57-63.

Boyle, K.J. (2003), 'Contingent Valuation in Practice', in Champ, P.A., Boyle, K.J. and Brown, T.C. (eds), A Primer on Nonmarket Valuation. Kluwer Academic Publishers, Dordrecht; 111-69.

Boyle, K.J., Desvousges, W.H., Johnson, F.R., Dunford, R.W. and Hudson, S.P. (1994), 'An Investigation of Part-Whole Biases in Contingent Valuation Studies', Journal of Environmental Economics and Management, 27, 64-83.
Carson, R.T. and Groves, T. (2007), 'Incentive and Informational Properties of Preference Questions', Environmental and Resource Economics 37, 181-210.

Carson, R.T., Louviere, J.J. and Wei, E. (2010), 'Alternative Australian Climate Change Plans: The Public's Views', Energy Policy, 38, 902-11.

Costantoura, P. (2007) How is Climate Change Creating a Social Shift and Driving Political Change? Presentation to the Annual Conference of the Climate Action Network Australia. Australian Research Group, Sydney.

Cummings, R.G. and Taylor, L.O. (1999), 'Unbiased Value Estimates for Environmental Goods: A Cheap Talk Design for the Contingent Valuation Method', American Economic Review, 89, 649-65.

Dellaert, B.G.C. and Stremersch, S. (2005). 'Marketing Mass-Customized Products: Striking a Balance Between Utility and Complexity', Journal of Marketing Research, 42, 219-27.

Dupont, D. (2004), 'Do Children Matter? An Examination of Gender Differences in Environmental Valuation', Ecological Economics, 49, 273-86.

Eagly, A.H. and Chaiken, S. (1993), The Psychology of Attitudes. Harcourt Brace and Co, Fort Worth, TX.

Edenhofer, O., Lessmann, K., Kemfert, C., Grubb, M. and Köhler, J. (2006), 'Induced Technological Change: Exploring its Implications for the Economics of Atmospheric Stabilsiation: Synthesis Report for the Innovation Modelling Comparison Project', Energy Journal, 27, 57-108.

Energy Futures Forum (2006), The Heat is On: The Future of Energy in Australia. CSIRO, Canberra.

Fiebig, D.G., Keane, M.P., Louviere, J. and Wasi, N. (2010), 'The Generalised Multinomial Logit Model: Accounting for Scale and Coefficient Heterogeneity', Marketing Science, 29, 393-421.

Greene, W.H. (1993), Econometric Analysis. Macmillan, New York.

Grubb, M., Hourcase, J-C., Edenhofer, O. and Nakicenovic, N. (2005), Framing the Economics of Climate Change: An International Perspective. Submission to the Stern Review on the Economics of Climate Change.

Guggenheim, D. (director) (2006), An Inconvenient Truth. Documentary film featuring Al Gore, Paramount Classics and Participant Productions.

Hatfield-Dodds, S., Jackson, E.K., Adams, P.D. and Gerardi, W. (2007), Leader, Follower or Free Rider? The Economic Impacts of Different Australian Emission Targets. The Climate Institute, Sydney, Australia.

Hoehn, J.P. and Randall, A. (1987), 'A Satisfactory Benefit-Cost Indicator From Contingent Valuation’, Journal of Environmental Economics and Management, 29, 121-32.

IPCC WG3 (2007). Climate Change 2007: Mitigation of Climate Change - Summary for Policymakers. IPCC/WMO/UNEP, Bangkok. 
Li, H., Berrens, R., Bohara, A., Jenkins-Smith, H., Silva, C. and Weimer, D. (2004a), 'Telephone Versus Internet Samples for a National Advisory Referendum: Are the Underlying Stated Preferences the Same?', Applied Economics Letters, 11, 173-6.

Li, H., Berrens, R., Bohara, A., Jenkins-Smith, H., Silva, C. and Weimer, D. (2004b), 'Would Developing Country Commitments Affect US Households' Support for a Modified Kyoto Protocol?', Ecological Economics, 48, 329-43.

List, J.A. (2001), 'Do Explicit Warnings Eliminate the Hypothetical Bias in Elicitation Procedures? Evidence from Field Auctions for Sportscards', American Economic Review, 91(5), 1498-507.

Lowy Institute (2005). Australians Speak 2005: Public Opinion and Foreign Policy. Report by Ivan Cook, March 2005. Lowy Institute, Sydney. $(\mathrm{n}=1000)$.

Lowy Institute (2006). Poll 2006 Australia, Indonesia and the World - Public Opinion and Foreign Policy. Report by Ivan Cook, October 2006, Lowy Institute for International Policy, Sydney. $(n=1007)$.

Morrison, M., Bennett, J. and Blamey, R. (1999), 'Valuing Improved Wetland Quality Using Choice Modelling', Water Resources Research, 35, 2805-14.

Murphy, J.J., Stevens, T.H. and Weatherhead, D. (2005), 'Is Cheap Talk Effective at Eliminating Hypothetical Bias in a Provision Point Mechanism?', Journal of Environmental and Resource Economics, 30, 327-43.

Newspoll (2007), 'Attitudes Towards Climate Change', Survey commissioned by The Australian, February 2007.

Olar, M., Adamowicz, W., Boxall, P. and West, G.E. (2007), 'Estimation of the Economic Benefits of Marine Mammal Recovery in the St. Lawrence Estuary', Final Report Prepared for Policy and Economics Branch, Fishery and Oceans Canada, Quebec Regional Branch, Fishery and Oceans Canada, Quebec.

Ostrom, E. (2005), Understanding Institutional Diversity. Princeton University Press, Princeton, NJ.

Pacala, S. and Socolow, R. (2004), 'Stabilization Wedges: Solving the Climate Problem for the Next 50 Years with Current Technologies', Science, 305 , 958-72.
Pocheptsova, A., Amir, O., Dhar, R. and Baumeister, R.F. (2007), 'Deciding Without Resources: Resource Depletion and Choice in Context', Journal of Marketing Research, 46, 344-55.

Preston, B.L. and Jones, R.N. (2006). Climate Change Impacts on Australia and the Benefits of Early Action to Reduce Global Greenhouse Emissions. Consultancy Report for the Australian Business Roundtable on Climate Change, CSIRO Marine and Atmospheric Research, Melbourne. [Cited 19 November 2010.] Available from: http://www. businessroundtable.com.au

Salisbury, L.C. and Feinberg, F.M. (2010), 'Alleviating the Constant Stochastic Variance Assumption in Decision Research: Theory, Measurement, and the Experimental Test', Marketing Science, 29, 1-17.

Stern, N. (2006), The Economics of Climate Change: The Stern Review. Cambridge University Press, Cambridge, UK.

Swait, J. and Adamowicz, W. (2001), 'Choice Complexity and Decision Strategy Selection', Journal of Consumer Research, 28, 135-48.

Swait, J. and Louviere, J. (1993), 'The Role of the Scale Parameter in the Estimation and Comparison of Multinomial Logit Models', Journal of Marketing Research, 30, 305-14.

Teal, G. and Loomis, J. (2000), 'Effects of Gender and Parental Status on the Economic Valuation of Increasing Wetlands, Reducing Wildlife Contamination and Increasing Salmon Populations', Society and Natural Resources, 13, 1-14.

The Climate Institute (2007), Climate of the Nation: Australians Attitudes to Climate Change and its Solutions. The Climate Institute, Sydney.

Train, K. (2003), Discrete Choice Methods With Simulation. Cambridge University Press, Cambridge.

Vohs, K.D. (2006), 'Self-Regulatory Resources Power the Reflective System: Evidence From Five Domains', Journal of Consumer Psychology, 16, 215-21.

Vohs, K.D. and Faber, R.J. (2007), 'Spent Resources: Self-Regulatory Resource Availability Affects Impulse Buying', Journal of Consumer Research, 33, 53747. 